\title{
Correspondence
}

DeAr Sir,

\section{PUERPERAL PSYCHOSIS}

The paper 'Postpartum Mania' by Kadrmas, Winokur and Crowe (Journal, December 1979, 135, 551-4) describing a number of patients with Schneiderian symptoms, raises questions of diagnosis, prognosis and treatment, and we would like to comment on these.

We are reviewing 32 patients with puerperal psychosis admitted to our Mother and Baby Unit during the last three years, and feel that this illness, especially in the early stages, should be described as a spectrum psychosis showing signs of affective, schizophrenic and organic features with rapid variation of symptoms. This clinical picture is similar to that produced by steroids used in the treatment of medical conditions and described by Hall et al (1979) who say "Steroid psychoses present as spectrum psychoses with symptoms ranging from affective through schizophreniform to those of an organic brain syndrome. No characteristic stable presentation was observed in these 14 cases reported here. The most prominent symptom constellation to appear some time during the course of the illness consisted of emotional lability, anxiety, distractibility, pressured speech, sensory flooding, insomnia, depression, perplexity, agitation, auditory and visual hallucinations, intermittent memory impairment, mutism, disturbances of body image, delusions, apathy, and hypomania".

A mother with postpartum mania should not be placed on prophylactic lithium. There are quicker, safer and more effective ways of treating her attack than with lithium, which is usually a slowly acting treatment requiring careful clinical and biochemical control. The quickest way of relieving the mother's symptoms (ideally in a Mother and Baby Unit) is desirable for the mental health of both mother and baby. Puerperal affective illnesses, including mania, are often tainted with the atypical features mentioned above. Patients with such symptoms are less likely to respond to lithium (Schou, 1968). The present attack may be the mother's first affective disorder and she may be symptom free for the next 20 or even $\mathbf{4 0}$ years. Generally, before using lithium, the patient should have had two or more episodes during the previous year, or one or more episodes per year during the previous two years (Kerry, 1975). Puerperal mania usually has a good prognosis thus contraindicating prophylactic lithium with its long-term side effects. Before, during and after childbirth one should not use lithium because of the alterations in kidney function and electrolytes, often considerable at these times. In addition to this it should be avoided in the foetus at birth and in the mother's milk during the puerperium.

There have always been arguments about the exact diagnosis in puerperal psychosis. We feel that the concept of spectrum psychosis simplifies the problem and points to hormonal influences.

JOAN SNEDDON

R. J. KERRY

Middlewood Hospital,

Sheffield S6 1TP

References

Hall, R. C. W., Popkin, M. K., Stickney, S. K. \& Gardner, E. R. (1979) Presentation of the steroid psychoses. The Journal of Nervous and Mental Disease, 167, 229-36.

KerRy, R. J. (1975) In Lithium Research and Therapy (ed. F. N. Johnson). London: Academic Press. Pp 154

ScHov, M. (1968) Lithium in psychiatric therapy and prophylaxis. Fournal of Psychiatric Research, 6, 67-95.

DeAR Sir,

\section{MATERNITY BLUES}

I would like to report a study of the incidence of 'Maternity Blues' in a group of 50 Tanzanian mothers. 'Maternity Blues' is a term used to describe the transient mood change which often occurs in mothers at some time during the third to tenth day after delivery (Victoroff, 1952; Yalom et al, 1968), and is characterized by tearfulness, irritability, hypochondriasis, sleeplessness and a feeling of confusion (Pitt, 1973).

The study is part of a larger one in which a group of Tanzanian mothers will be compared with a matched group from Cardiff. The fifty African mothers were seen at post-natal appointments, two to 
10 weeks after delivery, at Magomeni Health Centre in Dar Es Salaam. Mothers who saw themselves as having major socio-economic problems were excluded from the study, as also were unmarried mothers, those who said they were unhappily married, and those who had major ill-health, previous abnormal pregnancies and abnormal deliveries. In addition, the recent pregnancies and deliveries had to have been normal, and mothers had to be breast feeding mothers.

At interview, data were obtained concerning the mother working through the Middlesex Hospital questionnaire (because of cultural differences, some questions were considered inappropriate). 'Blues' were scored using a check list outlined by Brice Pitt, with a score of $0-4$ for each symptom.

A total of 38 out of 50 mothers showed some evidence of 'Maternity Blues' with a maximum incidence on the seventh day after delivery, and the remaining 12 showed no evidence of 'Maternity Blues'. When these figures were further broken down in terms of all the mothers, the following findings emerged.

Twenty-one mothers experienced weeping or a feeling of tearfulness, lasting from half an hour to a day at some point in the first two weeks after delivery, eight showed somatic features alone (without tearfulness) such as palpitations, air hunger, chest pains and sleeplessness, and nine experienced relatively minor symptoms such as a feeling of confusion, and irritability.

Preliminary analysis of results indicates a highly significant positive correlation of 'Maternity Blues' with the items of 'anxiety' and 'somatic symptoms' $(\mathrm{P}<.001)$, as measured on the Middlesex Hospital questionnaire.

These results show that 'Maternity Blues' is a cross cultural phenomenon and occurs in women from a culture which is quite different from that of Western countries. Preliminary comparison with a similar group from Cardiff showed a much stronger positive correlation of somatic symptoms (as measured on the MHQ) with 'blues' in the African group, so these results also illustrate the high degree of somatization of stress which characterizes East Africans.

Department of Psychiatry, Brian Harris

University Hospital of Wales, Cardiff, South Glamorgan

\section{References}

PrtT, Brice, (1973) 'Maternity blues'. British Joumal of Psychiatry, 122, 431-3.

Victoropr, V. M. (1952) Dynamics and management of parapartum neuropathic reactions. Diseases of the Neroous System, xiii, 10, 291.
Yalom, I. D., Lunde, Donald, T., Moos, R. H. \& HAMBURG, DAvid A. (1968) 'Postpartum blues' Syndrome. Archives of General Psychiatry, 18, 16-37.

\section{PLASMA AND RED CELL LITHIUM}

\section{Dear Sir,}

During the last few years, researchers on treatment with lithium for manic-depressive psychosis have been interested in biochemical parameters for an objective classification of the patients.

We have compared a group of 13 primary bipolar outpatients with 12 primary unipolar depressive outpatients, all being in remission for at least one year and taking therapeutic doses of lithium salts of $800-1,600 \mathrm{mg} /$ day. The plasma lithium concentration and red blood cell lithium concentration were determined 12 hours after the last dose was taken, following the method of T. B. Cooper et al (1974). When the Spearman's rank correlation coefficient was applied to correlate the plasma lithium and red blood cell lithium values in the two groups of patients, we found that the correlation coefficient was statistically significant $(P<0.05)$ in the bipolar depressive group, and nonsignificant in the group of unipolar patients (Table I). The same results were found when the determinations were made four hours after the

Table I

Correlation between plasma and red blood cell lithium concentration (Spearman's rank correlation coefficient)

\begin{tabular}{lcc}
\hline & $\begin{array}{c}\text { Four hours } \\
\text { after last } \\
\text { intake }\end{array}$ & $\begin{array}{c}\text { Twelve hours } \\
\text { after last } \\
\text { intake }\end{array}$ \\
\hline Total & $0.43^{*}$ & $0.66^{*}$ \\
Bipolar patients & $0.76^{*}$ & $0.73^{*}$ \\
Unipolar patients & 0.05 & 0.37 \\
\hline
\end{tabular}

$* \mathrm{P}<0.05$

last dose was taken. Lithium ratio (LR) data which are normally studied in most work in this field, do not show significant differences between the two groups of patients, so we are not able to establish any relation between this ratio and the clinical unipolar/ bipolar diagnosis of the patients.

It is not possible at the present time to draw conclusions from these results, but it is interesting to note that all the patients have homogeneous characteristics and have been in remission of their illnesses for a long time. Other parameters apart from lithium ratio could exist which would differen- 